\title{
Sobre el misterio estético en el texto literario: claves para una pedagogía de la literatura*
}

Fecha de recepción: 02 de septiembre de 2015

Fecha de aprobación: 11 de febrero de 2016

\section{Resumen}

El artículo considera algunas implicaciones propias del concepto misterio estético que, según Roger Chartier, aproxima ciertos elementos que gobiernan la producción y la recepción de los textos literarios. Ahora bien, para lograr tal fin, acudimos a reflexiones instaladas en la semiótica, la teoría literaria y la filosofía del lenguaje. Posteriormente, ensayamos las digresiones en el caso del personaje Rebeca, de Cien años de Soledad, apoyados en los principios metódicos sugeridos por Barthes, quien propone que todo texto debe ser analizado a la luz de una teoría liberadora del significante; y en Larrosa, para quien la lectura literaria instala una experiencia imaginativa transformadora. Los resultados de tal intervención dejan ver cómo el esfuerzo por demostrar una experiencia estética obliga a la labor de desenmascaramiento de la compleja red de asociaciones significantes que demoran la captura del sentido, al tiempo que sugiere claves para seguir enriqueciendo reflexiones pedagógicas sobre la enseñanza de la literatura.

Palabras clave: misterio estético, texto literario, espacio gnóstico, experiencia estética, pedagogía de la literatura.

Citar: García-Dussán, É. (enero-junio de 2016). Sobre el misterio estético en el texto literario: claves para una pedagogía de la literatura. La Palabra, (28), 141-154. doi: http://dx.doi.org/10.19053/01218530.4812

\section{Éder García-Dussán}

Universidad Distrital, FJC

Profesor e investigador de la Maestría en Pedagogía de la Lengua Materna, Universidad Distrital, FJC.

eagarciad@udistrital.edu.co egardus@gmail.com

* Artículo de reflexión, derivado de la investigación "El secreto de la laberíntica soledad. Sobre la identidad social en la producción del joven García Márquez", desarrollada en el programa Modelos de EnseñanzaAprendizaje y Desarrollo de las Instituciones Educativas, del Doctorado en Ciencias Sociales y Jurídicas de la Universidad de Granada. 


\section{About the Aesthetic Mystery in the Literary Text: Key Points for a Pedagogy of Literature}

\section{Abstract}

This article contemplates some implications of the concept aesthetic mystery, which, according to Roger Chartier, approaches elements that govern the production and reception of literary texts. To achieve this objective, we take into account reflections belonging to semiotics, literary theory, and philosophy of language. Subsequently, we incorporate these ideas into an analysis of the character Rebeca, in Cien años de soledad [A Hundred Years of Solitude], supported by methodical principles suggested by Barthes, who proposes that every single text must be analyzed in the light of a liberating theory of the signifier; and Larrosa, for whom literary reading installs a transformative experience of the imagination. The results show how the effort of demonstrating an aesthetic experience leads us to discover a complex web of meaningful associations that delay the capture of meaning, as well as suggest key points to continue enriching pedagogical reflections on the teaching of literature.

Key words: Aesthetic mystery, literary text, gnostic space, aesthetic experience, literature pedagogy.

\section{Sur le mystère esthétique dans le texte littéraire: des clés pour une pédagogie de la littérature}

\section{Résumé}

Cet article s'occupe du concept de mystère esthétique qui, selon Roger Chartier, gouverne la production et la réception des textes littéraires. Nous faisons appel à des réflexions sémiotiques, la théorie littéraire et la philosophie du langage. Par la suite, nous nous occupons de Rebeca dans Cents ans de solitude, à partir des principes méthodologiques de Barthes qui affirme que tout texte doit être analysé avec une théorie qui libère le signifiant, et sur Larrosa pour qui la lecture littéraire permet une expérience imaginaire transformatrice. Les résultats dévoilent le complexe réseau d'associations signifiantes qui retardent la capture du sens, et suggère les clés pour enrichir les réflexions pédagogiques sur l'enseignement de la littérature.

Mots clés: Mystère esthétique, texte littéraire, espace gnostique, expérience esthétique, pédagogie de la littérature. 


\section{Introducción}

En el otoño de 2007, el historiador francés Roger Chartier dictó su Lección Inaugural en el Colegio de Francia, dedicando un espacio para disertar sobre la historia de la cultura escrita y la literatura. Apostó, así, por calificar la literatura no sólo como un conjunto de textos que permiten poner el pensamiento en acción, sino que también suscitan el deseo humano. Aún más, citando al escritor argentino Jorge Luis Borges, añade que estos textos envuelven un "misterio estético" y una "magia" (Chartier, 2008, pp. 30, 32 ), cualidades que permiten, finalmente, definir el Texto literario como generador de un "encantamiento", esto es, un tejido sígnico que atrae al tiempo que entretiene ${ }^{1}$. De esta forma, Chartier promueve la reflexión sobre los acontecimientos que hacen posible vivir ese misterio y su connatural conjuro. Para discurrir sobre ello, ejemplifica rápidamente con el relato borgiano "El espejo y la máscara" (1975), pues para él en este relato se cosquillea un esquema pedagógico que admite concebir el Texto literario como una "poetización y sublimación de lo real" (p. 32) y que consiente experiencias estéticas (Chartier, 1997), las cuales permiten al lector completar, continuar, recrear y hasta reestructurar el Texto literario.

A partir de esto, nuestro propósito es, por una parte, explicitar y darle forma a los indicios que contiene el esquema de esa pedagogía literaria implícita en el relato borgiano, estudiando algunas posibilidades de comunicación del misterio estético que contiene y motiva la lectura de un Texto literario ${ }^{2}$ $\mathrm{y}$, por otro lado, encumbrar lo anterior como una de las claves esenciales para constituir un modelo funcional para la enseñanza de la literatura en la escuela. Así, tras el diseño de tal modelo, pondremos a prueba su firmeza, ejemplificando con un elemento textual confinado en Cien años de soledad (2012); a saber: los misterios de Rebeca, la hija adoptada de los Buendía. Todo esto nos permitirá rematar el esfuerzo insinuando que, a pesar de las claras limitaciones que poseen por natura todas las lenguas, la manipulación de los textos se esfuerzan por alcanzar Lo Real, cumpliendo con el arrojo de demostrar su función representativa, y que esto es aprovechable en la lectura literaria en la escuela, si se lleva a cabo como producto de un trabajo conjetural o abductivo, que asuma la materia significante de una manera particular $\mathrm{y}$, con auxilio de estrategias cotextuales, contextuales, intertextuales y extratextuales, permita pensar en un aprendizaje intercultural, e incluso interdisciplinar, de la literatura.

Hacia la mística de la experiencia estética

"El espejo y la máscara" es el séptimo relato borgiano de Libro de Arena, publicado en 1975, y se presenta como una breve pero compleja pieza metafísica, la cual relata la historia de la paulatina construcción de un poema que glorifica el triunfo bélico del Alto Rey en la Batalla de Clontarf, y que el mismo Rey de Irlanda solicita a su poeta, "El Ollán"3, cortesano del reino.

E1 primer poema entregado por parte del trovador es un fiel reflejo del suceso histórico, logrado con el uso de imágenes metafóricas primitivas; de ahí que el regalo otorgado por el rey fuera un espejo de plata.

\footnotetext{
En efecto, encantar, alude a atraer o agradar mucho, pero también tiene la acepción de "Entretener con razones aparentes y engañosas" (DRAE, edición 22. En línea).

2 Etimológicamente, misterio (del latín Mystérion) significa iniciado. En Roma, se asoció con rituales religiosos, donde sólo los iniciados podían actuar y beneficiarse de las plegarias y sacrificios allí desarrollados, y quienes tenían prohibido describir lo acontecido y vivido a los excluidos de tales actos. Por esto es que se conserva la asociación semántica de misterio entendido como "cosa oculta que no se puede conocer o explicar" (DRAE, edición 22. En línea).

3 Posiblemente el nombre Ollán tenga alguna relación con el mito irlandés de los duendes, llamados leprechones, quienes guardaban monedas de oro en una gran olla ubicada al final del arco iris, enterradas en periodos de guerras importantes.
} 
Aquí, el poema es imitación de la realidad; por tanto, sólo alcanza a ilustrar el suceso histórico. La segunda entrega fue un códice que no era la descripción de la batalla misma, sino que "[...] era la batalla" (Borges, 2007, p. 58). En este nuevo producto, el poema actúa como representación recreativa y ya no imitativa de la realidad, por lo cual la aprobación del rey fue manifiesta con un nuevo regalo; esta vez la ofrenda al poeta fue una máscara teatral de oro. El último poema, de una sola línea, nunca escrito y nunca repetido permitió, tanto al rey como al poeta, acceder a la idea misma de Belleza (el eidos platónico) y, tras la transgresión de los límites del lenguaje, el poeta se suicida con una daga, último regalo del rey, asegurando con este acto que su revelación sea incomunicable; mientras tanto, el soberano se condena al autoexilio y al peregrinaje taciturno.

Es de notar que en el apogeo del relato se incuba un misterio, pues ni el rey ni el poeta permiten ver al lector la línea poética, gracias a la visión interna (insight) lograda con el poema enunciado una sola vez, y mucho menos lo que estaba detrás de la línea; es decir, aquella línea efímera y pura que funda el mundo como verdadero no nos es conocida ni explicada. Esto permite asociar inmediatamente este último poema con la lengua adánica o lengua primitiva, aquella que nombró por primera vez cada cosa presente en su momento originario y que ha sido muchas veces buscada por los cultos religiosos desde el medievo, pues es la clave de acceso a la identificación del estado divino o estado absoluto que tiene el poder de establecer la realidad.

Así las cosas, el trasfondo del relato de Borges permite recrear una escena ficcional en la cual un hombre, El Ollán, accede, gracias a la lengua poetizada, a esa hipotética lengua a priori, perfecta, mágica, superior y originaria, y cuyo efecto es el acceso a la Verdad. De esta suerte, el poeta queda investido de la capacidad de superar la doxa e internarse en el orbe metafísico, aquel oculto que estudia Umberto Eco (1993), por cierto, al igual que Chartier, también inspirado en Borges. En efecto, el recién fallecido profesor Eco revela la obsesión de muchas empresas y personas quienes han perseguido desde hace siglos aquella lengua que recibió Adán en el Paraíso: una especie de lengua primordial con una gramática universal matriz de todas las demás lenguas; dicho de otra forma, un sistema de piezas simbólicas universales que pretenden explicar todo el contenido veraz del universo.

Así, por ejemplo, la escuela esotérica del cabalismo cristiano sostuvo que el hebreo era la lengua hierática por excelencia, pues sus fonemas y sílabas eran potencias generadoras y transformadoras ${ }^{4}$, mientras que Dante se preguntó cómo Adán habría establecido comunicación con Dios en el Paraíso terrenal ${ }^{5}$. También en estas discusiones intervino el filósofo alemán Leibniz, quien encontró la lengua perfecta en los códigos de la lógica matemática, mientras que los primitivos rosacruces creyeron ciegamente en la existencia de una lengua mágica, similar a la lengua de los pájaros. Mucho más recientemente, las ideas del filósofo Wittgesntein, en su Tractatus (1994), refiere que lo místico existe y, de hecho, es lo inexpresable, idea que jadeaba ya en las creencias de Mallarmé, Rimbaud o Joyce, expertos en trastocar las lenguas y en usar la alusión como estrategia de sus composiciones estéticas.

\footnotetext{
${ }_{4}$ Recuérdese aquí el bello poema de Borges, "El Golem" (1958), compilado en El otro, el mismo (1964), y que alude al medieval mito hebreo centrado en el poder creativo de la lengua. Así, pues, como Adán, un golem es creado con barro y su figura adquiere vitalidad al ser insuflado con sustancia significante como, por ejemplo, ciertas letras del alfabeto hebreo en la frente del animado de barro. Allí el golem es al rabino que lo creó, como el poema es al poeta.

5 Algunos intelectuales del siglo XVII pensaban que Adán y Dios hablaron en chino, porque los ideogramas comunican las mismas cosas, aunque su fonética sea equívoca; otros pensaban que hablaron en alemán, porque la naturaleza misma fanfarronea en ese idioma.
} 
Bajo este orden de ideas cultivadas históricamente, sostenemos que estos esfuerzos se resumen en la empresa borgiana con un poema unilineal, que atrapa y condena al tiempo y que, no por obra de la especulación sino de la tradición mística, puede pensarse como un poema de una sola palabra, quizá una del conjunto de los noventa y nueve nombres de Dios $^{6}$, permitiendo conocer La Idea de Belleza, ese don negado a los hombres?

Esta idea ha tenido varias resonancias seductoras. Por ejemplo, la idea de que la mediación poética descifra (interpreta) la realidad en su esencia, es asumida por el poeta cubano José Lezama Lima en su novela Paradiso (2011). Allí se narra la niñez y educación del poeta José Cemí, excusa actancial para sugerir una teoría poética que sostiene la existencia de una lengua materializada como prototipo absoluto del sentido, y que se logra cuando el lírico empolla el conocimiento poético, lo cual, nuevamente, alude a la captura de cierta empresa mística $\mathrm{y}$, por tanto, a ciertos rituales de iniciación donde las imágenes se vuelven materia significante con una función recreativa o reestructurante, permitiendo que la lengua natural y la lengua poética armonicen plenamente en beneficio de la configuración de Lo Real.

Es aquí donde resulta importante evocar aquella idea que subyace en el relato de Borges, citado por Chartier; nos referimos a esa apuesta pedagógica de El Ollán, ilustrada desde las poesías legendarias irlandesas (o Ciclos de Ulster y Munster, propios de la tradición celta) y que emplean “ $[. .$.$] las voces más$ arcaicas del idioma y las más complejas metáforas", además del uso de la "escritura secreta", materializada en composiciones poéticas como la "sátira" o los "panegíricos" (Borges, 2007, pp. 57-58). Todos estos recursos son los que le permiten al poeta borgiano encontrar, a lo largo de tres años, la ruta del conocimiento absoluto a través de una mediación prodigiosa, a saber: la de los nombres que ceden su arbitrariedad referencial y se reacomodan para conquistar el orbe de donde brotaron, ruta sólo posible si se apropia el reconocimiento de una tríada: "[...] -Somos figuras de una fábula y es justo recordar que en las fábulas prima el número tres", afirma la fábula de Borges en la voz del Alto Rey (p. 60).
Esto mismo le sucede al poeta Cemí de Lezama Lima. En efecto, Cemí contempla un objetoimagen junto a otro, provocando necesariamente la instalación de un tercer objeto que rehabilita la percepción y crea una imagen nueva, tal como sucede con la formación retórica de una metáfora, que reúne dos términosimagen para hacer corporal un tercer término espacializado en un topos textual. Esta resulta ser, entonces, una forma regia para reconfigurar un hecho al ser atravesado por las redes de la locución retórica, experiencia llamada por Lezama Lima espacio gnóstico; esto es, el acceso simbólico a un conocimiento de las cosas paradisíacas o divinas En suma, un saber trascendente que bordea y ajusta el carácter polisémico de las más de seis mil lenguas vivas en el globo terráqueo.

Asimismo, y siguiendo estas ideas preliminares, encontramos una reflexión que va por la misma vía en el premio Nobel de Literatura Octavio Paz (2000), para quien el lenguaje, mero depósito de representaciones (Dars-tellung $)^{8}$, toma un elemento de la realidad y lo encarna en otro que ya no es la experiencia fundamental de esa realidad,

\footnotetext{
Los noventa y nueve nombres de Dios son los epítetos usados por ciertos poetas del Islam para referirse a Dios (V. gr. iniciador, todopoderoso, santísimo...) y cuya existencia se atribuye al profeta Mahoma, quien afirmaba que Dios tiene cien nombres menos uno y que, quien los contara completos, entraría al Paraíso.

7 No resulta extraño ni extravagante entonces, seguir encontrado esfuerzos para la construcción de lenguas nuevas que intentan formalizar todo lo que hay en el mundo y en el pensamiento. Lenguas como la que salía a la luz en Caracas en 1988, prometiendo ser un sistema de escritura jeroglífica universal (Millán, 1996).

8 Darstellung, en alemán significa imagen mental (concepto); esto es, lo que sustituye una realidad.
} 
haciendo que "[...] el lenguaje tienda espontáneamente a cristalizar en metáforas" (p. 34), ya que éstas aprueban comprender "cualquier cosa en términos de cualquier otra" (Lakoff y Johnson, 1998, p. 15). Efectivamente, el lenguaje es un 'aparato metafórico', pues cada palabra termina siendo la cosa nombrada con la anuencia del enunciador. Pero este impulso retórico puede encauzarse a las experiencias artísticas, las cuales alteran los signos de los conceptos al fundar nuevas metáforas para recrear o configurar el mundo real, haciendo de éste un nuevo orbe. Es por eso que el encuentro con el Texto literario " $[. .$.$] supone un regreso$ al tiempo original. En este caso, al tiempo en el que hablar era crear. O sea: volver a la identidad entre la cosa y el nombre [...] una reconquista de la unidad primordial entre el mundo y el hombre" (Paz, 2000, pp. 35-36).

De ahí que resulte altamente importante la creación poética para Paz, pues a través de una especialización de la lengua en el Texto literario, el poeta devuelve al ser humano al momento primero donde éste crea la cosa/referente al relacionarla primariamente con una representación (un acto esencial que no obstante, necesita de la arbitrariedad y, por tanto, de una violencia primitiva). Para lograrlo, el poeta no tiene más remedio que ejecutar su acción comprometiendo el tesoro tradicional de las lenguas. Así pues, como afirmó Paz, lo primero que hace el escritor es desarraigar de sus vínculos tradicionales las representaciones, haciendo que los vocablos se vuelvan únicos $\mathrm{y}$, en un momento posterior, "[...] el poema se convierte en objeto de participación [...] es creación y recreación [...] el poeta transforma, recrea y purifica el idioma; y después lo comparte" (pp. 38-39).

Nótese que todo lo anterior (Lezama, Paz) está abreviado en una cita de Borges que recuerda Chartier en su discurso: "[...] Art happens (el arte ocurre) declaró Whistler, pero la conciencia de que no acabaremos nunca de descifrar el misterio estético no se opone al examen de los hechos que lo hicieron posible" (Chartier, 2008, p. 30) ${ }^{9}$. De esta suerte, y gracias al Texto literario, el misterio de toda experiencia estética reside en un hecho: que el lector de un texto logre, tras unos movimientos que comprometen su competencia lectora, un encuentro con el lenguaje puro que desarrolla el producto $y$, después, que recupere un sentido primitivo, la Verdad de Lo Real; experiencia que muchas veces resulta incomunicable, dado que el lenguaje público, cementerio de metáforas convencionales, 'no alcanza' habitualmente a describir el mundo subjetivo de la emoción, la sensibilidad y la experiencia vital que reporta a cada lector el texto de una obra ${ }^{10}$

La experiencia estética y la enseñanza de la literatura

A propósito, Umberto Eco sostuvo que un lector, que lee para comprender y con sus cinco sentidos, remueve experiencias pasadas de su stock de saberes frente a un estímulo (visual, táctil, olfativo, incluso gustativo), y tal empalme entre lo dado y lo puesto es lo que permite la construcción de un significado particular, acción que se convierte en un hecho a priori frente al acto lector. De esta suerte, "[...] sólo así concurre a dar forma a la experiencia en acto; la experiencia que no se limita así a señalar una Gestalt preexistente como autónoma configuración de Lo Real, sino que aparece como el resultado situacional de nuestra inherencia en el proceso del mundo" (Eco, 1992, p. 50).

$9 \quad$ Sin duda, Borges (1885) cita aquí una idea del pintor estadounidense James Whistler, precursor del arte abstracto, quien desarrolló la teoría pictórica del "Arte por el Arte", con el entendido de que el arte es la ciencia de la belleza.

10 A este respecto, la profesora de literatura Louise Rosemblatt (2000) afirma que una obra literaria siempre promete y hace actuar una experiencia. "[...] El poema, la obra de teatro, el cuento son, entonces, una extensión, una ampliación de la vida misma. El propósito principal del lector es añadir esta clase de experiencia a los demás tipos de experiencia deseable que puede ofrecer la vida (p. 298). 
En este orden de ideas, el asunto de la producción y comprensión de un Texto literario obliga a un trabajo minucioso de manipulación y de interpretación, abrigado por la experiencia auténtica y personal de alguien, pero asequible a otras experiencias. Sin embargo, la experiencia que tiene un lector con un texto arroja, la mayoría de las veces, uno de los dos recursos que esboza Borges: o bien el olvido, que es la verdadera muerte, o bien el acto de callarse (tacere: silencio de habla $)^{11}$, que sirve para evitar las trampas de la palabra, y que es una "[...] especie de virginidad intemporal de las cosas, antes de que estas nazcan o después de que hayan desaparecido (silentes = los muertos)", pero que, por ciertos avatares de la lengua, se "convierten en sinónimos" (Barthes, 2004, p. 67).

No obstante, la fe que tienen las propuestas pedagógicas de la literatura pueden orientar cierta formas de demostrar o enseñar ${ }^{12}$ aquellos plus de sentido que ponderan los lectores de las obras, pues finalmente Borges mismo ha comunicado lo incomunicable de la experiencia del poeta y el Rey, y lo ha hecho usando la lengua a través de recursos y estratagemas narrativas y descriptivas comunes a los hablantes del español. Así por ejemplo, una historia con personajes que ejecutan acciones cronológicamente, su fantasía inherente mezclada con el recurso datos históricos de la Irlanda de 1014 en cercanías a Dublín ${ }^{13}$, las comparaciones entre el Rey y el poeta con Eneas y Virgilio, la compleja red de significantes que tejen finos sistemas de relaciones de significación (espejos, máscaras, tríadas, etc.) con el uso de elementos intertextuales e interdisciplinares, como las bases filosóficas que evocan teorías esencialistas del lenguaje, etc.

A propósito de esto último, es útil subrayar que para Wittgesntein (1994), “[...] lo inexpresable ciertamente existe, se muestra, es lo místico" (p. 183). Es así como, para este filósofo austriaco, lo místico es el territorio de lo inexpresable, cercano a lo que el psicoanálisis lacaniano llama "Lo Real". Esto es, lo que está fuera del alcance del discurrir humano, pero también, y a su vez, es lo que se muestra; vale decir, lo que se pone a la vista de los demás y se explica, lo que se despliega ${ }^{14}$. De esta suerte, a pesar del aparente acallamiento que propone el filósofo, allí mismo se sostiene la posibilidad de decir lo indecible, lo que Barthes (1987) avizora con la siguiente advertencia:

$$
\begin{aligned}
& \text { [...] la "realidad" se } \\
& \text { muestra, lo "real" se } \\
& \text { demuestra; al igual que la } \\
& \text { obra se ve (en las librerías, } \\
& \text { en los ficheros, en los } \\
& \text { programas de examen), } \\
& \text { el texto se demuestra, } \\
& \text { se habla según ciertas } \\
& \text { reglas (o contra ciertas } \\
& \text { reglas); la obra se sostiene } \\
& \text { en la mano, el texto se } \\
& \text { sostiene en el lenguaje: } \\
& \text { sólo existe tomado en un } \\
& \text { discurso (o mejor: es Texto } \\
& \text { por lo mismo que él lo } \\
& \text { sabe); el Texto no es la } \\
& \text { descomposición de la obra; } \\
& \text { la obra es la cola imaginaria } \\
& \text { del Texto (p. 74). }
\end{aligned}
$$

Así, pues, esa zona de Lo Real, marcada como lo místico y lingüísticamente prohibida, supera o sobrepasa las redes del lenguaje. Es urgente, entonces, arremeter contra los límites del

11 Tacere, tacet: se calla. De ahí viene taciturno: callado, que le molesta hablar (DRAE, edición 22. En línea).

12 Demostrar. (Del lat. demonstrâre).tr. Manifestar, declarar. || 2. Probar, sirviéndose de cualquier género de demostración. || 3. enseñar (A mostrar o exponer algo). (DRAE, edición 22).

13 Recuérdese que la Batalla de Clontarf es un hecho histórico, sucedido el 23 de abril de 1014: El Alto Rey, Brian Boru, gobernador del antiguo reino irlandés de Munster, lucha contra los vikingos hasta vencerlos en una batalla que se consideró de todo un día. Lo único que no es fiel a la historia, es el destino final de Boru: éste es asesinado por un grupo de nórdicos que huían y se encontraron por casualidad con su tienda, mientras el rey rezaba. Los historiadores, no obstante, subrayan que con frecuencia la biografía del Alto Rey mezcla ficción y realidad.

14 Explicar (del latín explicare) es ex - plegar, sacar los pliegues hacia afuera; más simplemente, desenrollar. Por tanto, implicar es lo contrario, mientras que complicar es hacer muchos pliegues. 
mundo y, por tanto, las demarcaciones del lenguaje que da cuenta de él. Aunque pueda creerse que ese ir más allá sea una labor desesperanzada, hay que arremeter contra el silencio porque, al fin y al cabo, "el lenguaje no es una jaula" (Wittgenstein, 1990, p. 50). Y para avanzar en tal fin, están a disposición de todos los amantes de la literatura habilidades que se pueden enlistar para reconstruir una pedagogía literaria que nos obliga, por lo menos, a concebir y proceder en el ámbito de la enseñanza y el aprendizaje desde algunas premisas cardinales, a saber:

1- Toda obra encierra un Texto secreto, y tal enigma no es otra cosa que un plus de sentido que se reconstruye de un modo enigmático; de hecho, la obra se pone al servicio de ese Texto que por su propia naturaleza, está cifrado.

2- El Texto literario es un corpus, esto es, como un cuerpo sensible que por su naturaleza se puede desmigajar lúdicamente, puesto que es un producto que teje intenciones, voces y contextos cognitivos. En suma, el Texto literario es semiosis, "[...] es decir, una puesta en escena de lo simbólico, no del contenido, sino de sus desvíos, retornos; en resumen, los goces de lo simbólico" (Barthes, 1983, p. 247); y también es un texto abierto e infinito que debe ser analizado a la luz de una "teoría liberadora del significante", ya que remite "de un significante a otro, sin cerrarse jamás" (p. 250) ${ }^{15}$.

3- Sin pretensiones de renunciar a la exposición de hechos de semiosis ni a la explicación, la experiencia estética y su mística pueden ser escuchadas sin un control tradicional que las reduzca a una exclusiva labor cognitiva, pues de ser así el Texto quedaría sometido a un cuerpo-del-delito; por lo que hay que convertir su corpus sensible en un cadáver para, así, diseccionarlo y proceder a su análisis cauteloso. No se trataría entonces, como han hecho las didácticas de la lengua y la literatura tradicionalmente, de tomar el Texto como el biólogo con el tejido, sino de (de)mostrar cómo su semiosis desestabiliza, afecta a un lector, puesto que "[...] el texto es portador de un pneuma, de un ánimus, o de un spiritus [...] que al mezclarse con la sustancia etérea del alma, la conforma, la transforma o la deforma" (Larrosa, 2003, p. 46), lo cual permite que el encuentro con el Texto literario se convierta en un acontecimiento que, al afectar la subjetividad, implica detenerse a escuchar activa y creativamente Lo Real que el texto informa ${ }^{16}$.

La literatura es una experiencia lectora, de suerte que si la formación lectora es asumida como experiencia (Larrosa, 2003), fractura los contornos entre imaginación y realidad mientras afirma la potencia transformativa de la subjetividad. Transformaciones que pueden representarse con metáforas, como aquellas que Larrosa instala en los discursos pedagógicos y que son imágenes posibles de la experiencia estética, a saber: la de fármaco, la de viajero o la del traductor. Esto es, la experiencia donde el texto actúa como una medicina para el alma, donde el texto actúa como un mapa para no perderse; o, finalmente, aquella donde el texto nos lleva a otros códigos idiomáticos y nos obliga a ajustar lo foráneo con lo local.

De esta suerte, y a partir de toda esta digresión teorética, nos atrevemos a comprender la experiencia estética como el resultado de un ejercicio de lenta laboriosidad, cuyo punto de inicio y anclaje es la percepción sensible (Eco, 1992), y cuyo clímax es la confirmación de la existencia

15 Como lo diría después el mismo Barthes, todo texto es una campo metodológico que "[...] sólo se experimenta en un trabajo, en una producción" (Barthes, 1987, p. 74) y, que se descubre siempre "detrás del límite de la doxa“ (p. 75).

16 Lugarini (1996) propone cuatro tipos de escucha, desde la distraída hasta la crítica, pasando por la dirigida y la creativa. Esta última exige del interlocutor la reminiscencia rápida de datos (enciclopedia o stock de saberes) relacionados con la situación que intenta comprender, al tiempo que presupone la actividad simultánea tanto del pensamiento convergente o lógico, como del pensamiento divergente o lateral, requisitos cardinales para que se instituya una comprensión sobre lo que sucede en los escenarios escolares comunicativos. 
de una gnóstica (Lezama) o de una mística (Wittgenstein) que alerta sobre la falsedad de la univocidad de los significantes y que terminan, tras su paso caprichoso y exagerado por las tramas multitopológicas de la lengua, por insistir en un más allá de las líneas, transformando la relación de la tríada lectortexto-contexto en un acto donde lo importante es trascender lo visible-inmediato y construir un plus de sentido que, algunas veces, conduce a prolongar los silencios; y otras, a azuzar la discusión y la defensa de un punto de vista.

Sobre una experiencia estética: el caso de Rebeca Buendía en Cien años de soledad

Pese a que las deducciones anteriores y su tesis resultante pueden llegar a ser abstractas y engorrosas, creemos que se pueden concretar y ejemplificar en beneficio de un piloto exploratorio que se pueda aterrizar en las aulas de lengua castellana. Así pues, tomaremos un punto actancial de la obra magna de Gabriel García Márquez y su compleja trama; a saber: el personaje de Rebeca Buendía, como ilustración de cómo se puede liberar un significante, romper el silencio y actuar en beneficio de una intuición que se convierte en una mística o una gnóstica.

Lo primero que hay que advertir es que Rebeca no es una creación de Cien años de soledad; ya aparece en el cuento Un día después del sábado, escrito por García Márquez en 1954 y que hace parte de uno de los ocho relatos compilados en Los Funerales de la Mama Grande (1962/2012b), como ya lo había advertido Wahnón (1998), lo cual revela una continuación histórica de ella en el cuento y en la novela. En efecto, allí el personaje de Rebeca es presentado por primera vez como la viuda de José Arcadio Buendía hijo y, desde la perspectiva del párroco del pueblo, Antonio Isabel, es una mujer enigmática. Pero, sin duda, el actante Rebeca cobra toda su fuerza en el topos de aquel pueblo tropical, Macondo, trece años después.

Ahora, este personaje, significante liberado y campo metodológico de una posible semiosis (Barthes), llama la atención porque en la trama de la novela genera al menos cinco misterios que, de hecho, no son resueltos ni en el circuito interno del enmarañado textual cuentístico ni novelístico de García Márquez, ni en la lectura rápida e inocente que se puede hacer de su obra, analizada como progresión desde 1947 hasta 1967. Estos misterios son:

1- La genealogía familiar de Rebeca; esto es, su infancia remota en una antigua localidad de la Guajira.

2- La justificación de por qué es Rebeca quien se convierte en el 'caso cero' de la peste del olvido, una fatalidad contagiosa que refuerza la imposibilidad de reconstruir, incluso, su propio pasado infantil.

3- La muerte de su esposo, José Arcadio Buendía.

4- La relación de Rebeca con el Judío Errante cuando este pasa por el pueblo, ocasión en la que sale Rebeca de su autoencierro tras quedar viuda.

5- La asociación de la muerte de Úrsula, un Jueves Santo, con la llegada de una oleada de calor y la muerte de pájaros en Macondo.

Así las cosas, es factible impulsar estratagemas que coadyuven a demostrar o explicar las razones que mueven a Rebeca a ser ese significante que oculta un misterio de cinco aristas; aún más, a preguntar por la posibilidad de liberar ese significante de su tejido primitivo u original, como afirma Paz y, como indica Barthes, para ver su semiosis en el texto de la obra garcía-marquiana. Como es notorio, aquí lo místico se hace palpable y obliga al lector a romper el silencio y espantar el olvido de hechos diegéticos, evidentemente turbadores para los lectores.

En ese intento por desenmascarar el misterio, de suyo entretenida acción cuasiforense, lo primero que advertimos es que a Rebeca la conocemos como una niña, no mayor de 12 años, proveniente de Manaure (Municipio de La 
Guajira), y quien fue entregada a José Arcadio Buendía por unos traficantes de pieles. Lo otro que resulta interesante es que de entre sus trebejos resaltaba una lona que conservaba los huesos de sus padres, sin que ella supiera nunca su contenido ${ }^{17}$. Una carta que la acompañaba, afirmaba hacer caridad con la huérfana, familiar lejana de los Buendía, aunque "[...] ni José Arcadio Buendía ni Úrsula recordaban haber tenido parientes con esos nombres ni conocían a nadie que se llamara como el remitente y mucho menos en la remota población de Manaure" (García Márquez, 2012, pp. 48-49). Esto no impidió que Rebeca se acoplara con los otros niños de la casa, Arcadio y Amaranta, hasta que una noche la india Visitación reconoció en sus ojos la peste del Insomnio, manifestando entonces "[...] que lo más temible de la enfermedad del insomnio no era la imposibilidad de dormir, sino su inexorable evolución hacia una manifestación más crítica: el olvido", síntoma que dejaba al afectado "[...] en una especie de idiotez sin pasado" (p. 51); cuestión que le sucedió a la misma historia de Rebeca años después, pues García Márquez finiquita se presencia en los avatares de Macondo, así: "El pueblo la olvidó” (p. 139).
Rápidamente surge la pregunta sobre las razones que justifican el hecho de que sea justamente Rebeca quien traiga el olvido a Macondo. Pregunta válida puesto que es cómodo asociar la circunstancia con el alífero olvido del origen de ella por parte de la familia Buendía y del mismo lector, quienes, desde circuitos enunciativos diferentes, la aceptamos en el seno de la familia macondiana y esto muy a pesar de que sea justamente Rebeca quien desgracia la vida amorosa de Amaranta.

Como se sabe, al crecer Rebeca se generó una rivalidad femenina descomunal con su hermanastra Amaranta por causa de su apego simultáneo a Pietro Crespi; pero, con la llegada de José Arcadio hijo de su autoexilio prolongado, Rebeca se casó con él y, tras la negativa de Úrsula a que vivieran en la casa por la "inconcebible falta de respeto" (p. 100), moraron un tiempo en una casita alquilada, cerca al cementerio de Macondo. Es en su interior donde "[...] el carácter firme de Rebeca, la voracidad de su vientre, su tenaz ambición, absorbieron la descomunal energía del marido, que de holgazán y mujeriego se convirtió en un enorme animal de trabajo" (p. 118). Tiempo después se mudaron a una casa construida por Ar- cadio, “[...] situada en el mejor rincón de la plaza, a la sombra de un almendro" (p. 136), donde se manifestaba la laboriosidad de José Arcadio a través de una ritual actividad de caza. Así trascurrió un periodo conyugal aparentemente armónico hasta que, una tarde de septiembre, el hombre volvió a casa más temprano que de costumbre, se fue al dormitorio y luego se escuchó un disparo sin que Rebeca, según su versión, lo presenciara. Entonces, se lee en la novela:

[... Ese fue tal vez el único misterio que nunca se esclareció en Macondo. Tan pronto como José Arcadio cerró la puerta del dormitorio, el estampido de un pistoletazo retumbó en la casa [...] Tan pronto como sacaron el cadáver, Rebeca cerró las puertas de su casa y se enterró en vida, cubierta con una gruesa costra de desdén que ninguna tentación terrenal consiguió romper. Salió a la calle en una ocasión, ya muy vieja, con unos zapatos de color de plata antigua y un sombrero de flores minúsculas, por la época en que pasó por el pueblo el Judío Errante (pp. 137-139).

\footnotetext{
17 Cuestión, por demás, interesante, pues alude de forma muy sutil a aquellos sacrificios domésticos y rituales de fundación de urbes donde las comunidades, para certificar su estabilidad y vida funcional trataban con huesos"[...] depositados bajo o junto a los muros de algunas casas de la edad del hierro en diversas áreas de la península ibérica y [...] vinculados con el hogar doméstico" (Almagro y Lorrio, 2011, p. 48).
} 
Lo único cierto es que, de esta forma, el tejido narrativo de Cien años de soledad (1967) permite vislumbrar los otros tres misterios que envuelven a este actante. En relación con el misterio de la muerte de José Arcadio, sabemos por Cien años de soledad, que no "[...] encontraron ninguna herida en su cuerpo, ni pudieron localizar el arma. Tampoco fue posible quitar el penetrante olor a pólvora del cadáver" (2012, p. 138); sólo se supo que de su oído derecho fluyó el mágico hilo de sangre que llegó a Úrsula.

Todo esto mientras que en el cuento (1954) este misterio molesta al clérigo Antonio Isabel, puesto que Rebeca le respondía "[...] con evasivas cuando él trataba de concretarla acerca de la oscura muerte de su esposo" (García Márquez, 2012b, p. 198), lo cual permite especular a vuela pluma sobre las razones secretas que hubiera tenido Rebeca para asesinar a su esposo. Aparentemente no existen motivos, pues en la novela hay datos que demuestran cómo José Arcadio la hizo feliz como mujer; baste recordar las intensas descripciones de sus noches de comercio carnal y que, gracias a las faenas logradas en el tálamo, lo tenía sumiso, casi plomizo, haciendo palpable la charada de José Arcadio Buendía cuando afirmaba contundentemente que "El amor es una peste" (García Márquez, 2012, p. 76). A pesar de todo esto, no es gratuito que el cadáver emitiera olor a pólvora a pesar de las acciones para evitarlo, pues es sabido que ésta es el símbolo moderno de la esclavitud física y moral, que todo colonizador usó para absorber y someter.

Pero si este hecho es fascinante, la relación de Rebeca y el Judío Errante lo es mucho más. La leyenda del Judío Errante, asentada en el siglo XIII, se refiere a un viejo condenado a viajar eternamente por el mundo, sin esperanzas de descansar en paz, mientras ocurre la segunda llegada de Jesucristo a la tierra (la parusía); hecho que, de forma mística, se toca, por lo menos, con cuatro confusiones enigmáticas contenidas en la secreta historia de Rebeca:

(i) El hecho de que, "según le habían contado", su bisabuelo se había "ido a rodar por el mundo entero" (García Márquez, 2012b, p. 210).

(ii) El encierro de Rebeca en su casa de "interminables corredores" (p. 210), que pinta un escenario donde parece autosancionada por haber hecho algo malo, arrastrando consigo una condena por pecadora, y "destinada a morir en el pueblo"; como sucede con el propio Judío Errante y que, de alguna manera, comparte la cualidad actancial asociada con la maldad (lo bestial, lo infernal).

(iii) El conocimiento que Rebeca tiene desde su "remota infancia" vivida en Manaure sobre el Judío Errante (2012b, p. 198), y que asocia ella misma con la muerte de los pájaros en Macondo. Cuestión que, por cierto, se desestima teniendo en cuenta que esta parte específica de la historia reaparece en Cien años de soledad, donde el pueblo atrapa e incinera al Judío Errante y se da cuenta que, "[...] contrario a la descripción del párroco, sus partes humanas eran más de ángel valetudinario que de hombre" (García Márquez, 2012, p. 341), por lo que, finalmente, "[...] nunca se estableció si en realidad fue por él que se murieron los pájaros" (p. 342).

(iv) "La verdad" de la que se dio cuenta el Padre mientras relata su encuentro con el Judío Errante (2012b), y que se puede leer como si Rebeca, al entrar a la iglesia, encarnara el advenimiento del mismísimo Cristo crucificado (parusía): "[...] Vio que había gente en la iglesia y que por la nave central avanzaba la señora Rebeca, patética, espectacular, con los brazos abiertos, y el rostro amargo y frío vuelto hacia las alturas" (García Márquez, 2012b, p. 212). Sobre esto último, el lector atento se inclinaría por concebir a Rebeca como la carne histérica de una representación local del Cordero de Dios, pues mientras Rebeca camina hacia él por la nave central de la iglesia, algo que reprime al Padre pensar que asistía a un Milagro, este afirma 
"[...] Detente. Nunca ha sido buen día sacrificar un cordero" (p. 212).

Así pues, es de notar que los misterios contenidos en el significante 'Rebeca' dentro de la fascinante trama de la obra de García Márquez, no alcanzan el premio de una disolución, puesto que el tratamiento aquí logrado parece identificarse en algunos momentos con el Judío Errante (y este con el mal -el diablo- algunas veces y según cierta voces, y con el bien -el ángel- en otras, si creemos en las evidencias del pueblo macondiano), y en otros momentos con el mismísimo Cordero de Dios.

\section{Nota sobre la confusión y el extravío}

Rebeca resulta ser un significante aparentemente inocente, pero la detención en su compleja red de contrariedades nos ha llevado a bordear un ingente misterio y nos ha obligado a entrar y salir de la obra para desentrañar el Texto, al decir de Barthes. No obstante, el milagro ${ }^{18}$ de una captura de sentido sobre ese vacío, ese hueco en la comprensión, estaría situada en la posibilidad de privilegiar uno de los dos rostros de Rebeca, ora el bondadoso, ora el malvado.
Por cierto, esta ha sido desde hace mucho una ambivalencia presente en los rostros de las mujeres místicas dentro de los sistemas religiosos y hasta los mitos dan cuenta de ello. Por ejemplo, en la mitología Sumerio-babilonia, Ishtar, diosa que se identifica con las fases del planeta, como estrella matutina es una virgen, como estrella vespertina es una prostituta, como señora del cielo de la noche es la concubina de la luna, y cuando se extinguen bajo el brillo solar es la bruja del infierno (Campbell, 1980). Doble naturaleza que también aparece en Kalí, diosa hindú que simultáneamente es promiscua $\mathrm{y}$ virginal, al igual que sucede con Inanna, diosa Sumeria, deidad del amor y la destrucción (Hernández, 1972). Así las cosas, el hecho de mostrar esta doble y contraria naturaleza instalada en la feminidad, permite confirmar que es en este orbe donde disimula u oculta misteriosamente la verdad de su (falta de) ser bajo diversas máscaras (otra vez la máscara, aquel regalo del Rey al poeta).

Al apropiarse de la máscara, la mujer aquella donde algo es lo nombrado (como en las posturas esencialistas del griego Cratilo) oculta la Verdad, mantiene el misterio, esconde la propiedad de lo buscado bajo sus velos y sus actuaciones, razón que le permite a Derrida (1981) afirmar que:

[...] en cuanto modelo de esa verdad, la mujer se convierte en el modelo que representa la disimulación, el adorno, la mentira, el arte, la filosofía artista [y para ello] goza de un poder de seducción que subyuga al dogmatismo, extravía y espolea a los hombres, los crédulos, los filósofos" (p. 45 , negrita nuestra $)^{19}$.

De esta suerte, el recorrido nos deja callados; aunque, es de notar, ya lo hemos comunicado. Dicho de otra forma: hemos partido de una experiencia estética mística, tratando de comprender el secreto del Alto Rey y su poeta, para terminar con los misterios que tiene en sus manos Rebeca Buendía. Ahora, el asunto entre ojo y ojo del lector se convierte en un intento de explicar o notificar sus acciones, pero esto ha resultado un experimento comunicativo entredicho; vale decir, una torpeza que apenas crea aproximaciones, destellos e intuiciones, tras la decisión de traspasar los límites mismos del lenguaje (Wittgenstein).

\footnotetext{
Milagro viene del latín miráculum, que es mirar con asombro.

19 También podríamos decirlo en términos más escuetos, siguiendo a Nietzsche: “¿Qué resulta siempre de esto? Que hasta cuando se entregan están "representando": ¡Es tan artista la mujer!" (2002, libro V, 361, p. 155).
} 


\section{A manera de conclusión}

Abreviando este esfuerzo, tenemos que expusimos ${ }^{20}$, siguiendo el bravío empuje del joven Wittgenstein y la certeza de Derrida ${ }^{21}$, todo esto para finiquitar con un halo de parcial naufragio, pues el universo simbólico, esa gran madre que nos cobija a todos, insiste en desobedecer a los dictados de la apropiación del mundo porque, a pesar de los esfuerzos, entre sus casillas semántico-pragmáticas, escapa a la unicidad dentro de lo múltiple, entendiendo de paso por qué hay mil y una noches en la literatura. Es así como se alude a una peculiar relación entre las palabras y las cosas que superan la representación o la ilusión y se inscriben en el universo del misterio, como en el último poema del cuento borgiano.

De esta suerte, certificamos, por un lado, que la experiencia estética aparece como el efecto de un ejercicio que forma lectores iniciados, quienes toman conciencia sobre la capacidad figurativa e indexical de la lengua, los mantiene en un sutil nerviosismo y lo instiga a buscar una materia constituyente escondida o misteriosa con la cual trabajar conjeturalmente. El premio es un cierto alivio o distensión, producto de la ratificación de la existencia de una gnóstica o de una mística que alerta sobre la arbitrariedad de la cadena significante, generando así la posibilidad de romper el silencio con el ofrecimiento de hipótesis de sentido que intentan dar solución a los secretos textuales, y que quedan como evidencia de una lectura que impacta y transforma. Este camino comprensivo de trabajar la experiencia lectora que es la literatura en la escuela, asegura no sólo leer literatura, sino enseñarla y aprenderla de otra forma, superando así lo que habitualmente se encuentra en nuestras aulas: memorización de títulos y fechas, llenado de fichas mnemotécnicas con datos literales, escritura estereotipada sin receptores hipotéticos y sin posibilidad de debatir o dejarse, al menos, interrogar y transfigurar.

Pero, por otra parte, lo anterior se desgaja para constituirse como clave para una pedagogía de la literatura, que se centra en la actitud del receptor de la obra-texto, lo que esboza un tipo de lector que se enfrenta a las máquinas literarias con mejores cajas de herramientas, y con la paciencia de un viejo que se permite destejer y volver a tejer, como Penélope, los hilos de sentido. Así las cosas, la actitud del lector es la que Nietzsche ratificó en su Zaratustra $(2011)^{22}$, y la que se afirma desde la empresa semiótica y que invita a apropiarse de tres acciones: rumiar, conjeturar y discutir (discurrir). A lo cual se puede adherir, a secas, desautomatizar, dada la tendencia a leer experimentos creativos, muchos de ellos harto problemáticos pero, en todo caso, irrenunciables cuando se piensa en enriquecer premisas que ayudan a concebir presencia, utilidad y circulación de la literatura en la Escuela ${ }^{23}$.

Exponer (ex ponere): colocar algo donde pueda ser visto.

21 "En adelante no podrá buscarse la mujer, la femenidad de la mujer, la sexualidad femenina. Al menos no podrá encontrarse mediante una modalidad conocida del concepto o del saber, incluso en el caso en que no se pueda dejar de buscarlas" (Derrida, 1981, p. 40).

22 "Mientras no nos convirtamos y nos hagamos como vacas no entraremos en el reino de los cielos. De ellas deberíamos aprender, en efecto, una cosa: el rumiar. Y, en verdad, si el hombre conquistase el mundo entero y no aprendiese esa única cosa, el rumiar: ¡de qué le serviría! (Nietzsche, 2011, p. 54).

23 Piénsese, por ejemplo en novelas que se conforman con la fusión de titulares de prensa, en productos que se hacen visibles al modificar las tipografías, como aquellas obras que exigen ser leídas con lupa, o aquellas que perturban un texto ya establecido como literario y sagrado, dejando la sensación de su 'profanación'. 


\section{Referencias}

Almagro, M. y Lorrio, A. (2011). Teutates, el héroe fundador y el culto heroico al antepasado en Hispania y en la Keltiké. Madrid: Real Academia de la Historia.

Barthes, R. (1983). Literatura / enseñanza. En: Lo neutro. Notas de cursos y seminarios en el Cóllege de France, 1977-1978 (pp. 242-251). México: Siglo XXI.

Barthes, R. (1987). De la obra al texto. En: El susurro del lenguaje. Más allá de la palabra y la escritura (pp. 73-82). Barcelona: Paidós.

Borges, J.L. (2007). Obras completas (3 Tomos). Buenos Aires: Emecé.

Campbell, J. (1980). El héroe de las mil caras. México: Fondo de Cultura Económica.

Chartier, R. (1997). Pluma de ganso, libro de letras, ojo viajero. México: Universidad Iberoamericana.

Chartier, R. (2008). Escuchar a los muertos con los ojos. Lección inaugural en el Collége de France. Madrid: Katz.

Derrida, J. (1981). Espolones. Los estilos de Nietzsche. Valencia: Pretextos.

Eco, U. (1992). La obra abierta. Buenos Aires: Planeta.

Eco, U. (1999). La búsqueda de la lengua perfecta. Madrid: Crítica.

García Márquez, G. (2012). Cien años de soledad. Bogotá: Norma.

García Márquez, G. (2012b). Gabriel García Márquez. Todos los cuentos. Buenos Aires: Mondadori/ Sudamericana.

Lakoff, G. y Johnson, M. (1986). Metáforas de la vida cotidiana. Madrid: Cátedra.

Larrosa, J. (2003). La experiencia de la lectura. México: Fondo de Cultura Económica.

Lezama Lima, J. (2011). Paradiso. Madrid: Alianza editorial.

Lugarini, E. (1995). Hablar y escuchar. Por una didáctica del "saber hablar" y del "saber escuchar". Signos: teoría y práctica de la educación, (14). Recuperado de http://www.quadernsdigitals.net/ datos/hemeroteca/r_3/nr_42/a_638/638. html

Millán, J.A. (1996). Húmeda Cavidad, seguido de rosas y puerros. Salamanca: Ediciones Universidad de Salamanca.

Nietzsche, F. (2002). La gaya ciencia. Madrid: Akal.

Nietzsche, F. (2011). Asi habló Zaratustra. Madrid: Alianza.

Paz, O. (2000). El arco y la Lira. Bogotá: Fondo de Cultura Económica.

Real Academia Española. (2016). DRAE. (ed. 22). Disponible en: www.rae.es

Rosenblatt, L.M. (2002). La literatura como exploración. México: Fondo de Cultura Económica.

Wahnón, S. (1998). El Judío Errante en Cien años de soledad. En: G. Pardo (Comp.). Memorias XX Congreso Nacional de Literatura, lingüística y semiótica: "Cien años de soledad”, treinta años después (pp. 41-60). Bogotá: Instituto Caro y Cuervo - Universidad Nacional.

Wittgenstein, L. (1994). Tractactus Lógico Philosophicus. Barcelona: Altaya.

Wittgenstein, L. (1990). Conferencia sobre ética. [Con dos comentarios sobre la teoría del valor]. Barcelona: Paidós. 